\title{
ОСОБЕННОСТИ ИММУННОГО ОТВЕТА
} У БОЛЬНЫХ С ОБОСТРЕНИЕМ ХРОНИЧЕСКОГО ВЕРХНЕЧЕЛЮСТНОГО СИНУСИТА, СОПРЯЖЕННОГО С ВНУТРИКЛЕТОЧНОЙ БАКТЕРИАЛЬНОЙ ИНФЕКЦИЕЙ

\author{
О.В. Парилова ${ }^{1,2}$, Т.А. Капустина ${ }^{1}$, А.Н. Маркина ${ }^{1}$, Е.В. Белова ${ }^{1}$ \\ ${ }^{1}$ ФГБНУ НИИ медицинских проблем Севера, г. Красноярск, Россия \\ ${ }^{2}$ ФГБОУ ВО Хакасский государственный университет им. Н.Ф. Катанова, г. Абакан, Россия
}

Резюме. Хроническая воспалительная патология околоносовых пазух является в настоящее время одной из актуальных проблем современного здравоохранения, при этом наиболее часто патологический процесс локализуется в верхнечелюстной пазухе. Последние два десятилетия все большее этиологическое значение в инициации воспаления слизистых оболочек околоносовых пазух придается бактериальной внутриклеточной инфекции - микоплазменной и хламидийной. При этом хламидии, чей жизненный цикл связан с непосредственным нахождением в клетках хозяина, являются патогенными облигатными внутриклеточными грамотрицательными бактериями, в то время как микоплазмы - это мембрано-ассоциированный микроорганизм, способный к саморепликации и длительной персистенции на мембранах клеток макроорганизма. Увеличение роста хронической патологии околоносовых пазух, сопряженной с внутриклеточной инфекцией, определяется многими обстоятельствами, прежде всего увеличением числа иммунокомпрометированных лиц, ухудшением социальных и экологических условий жизни, бесконтрольным и необоснованным применением современных антимикробных и антисептических, гормональных средств, нарушающих совокупность внеклеточных микробных популяций (микробиоценозов), населяющих естественный биотоп слизистых оболочек верхних дыхательных путей. Эти факторы способствуют снижению колонизационной резистентности, внедрению и размножению хламидий и микоплазм в виде моно- или микст-инфицирования. При этом смешанные варианты хламидийно-микоплазменной инфекции характеризуются развитием более тяжелых форм синуситов с развитием разнообразных осложнений со стороны нижних дыхательных путей, пищеварительного тракта, мочеполовой и нервной систем. Для определения эпидемиологической характеристики и особенностей системного и мукозального иммунных ответов у больных с обострением хронического верхнечелюстного синусита, сопряженного с внутриклеточной бактериальной инфекцией, было обследовано 189 человек. Наличие внутриклеточной бактериальной инфекции подтверждалось лабораторными тестами: прямым иммунофлуоресцентным анализом и полимеразной цепной реакцией. Анализ результатов исследования показал у пациентов с обострении хронической воспалительной патологии околоносовых раковин высокую частоту выявления Chlamydia trachomatis, Chlamydophila pneumoniae, Mycoplasma pneumoniae. При сравнении результатов лабораторных исследований больных с идентифицированной внутриклеточной бактериальной

\section{Адрес для переписки:}

660022 , Россия, г. Красноярск, ул. Партизана Железняка, 3г, НИИ медицинских проблем Севера.

Тел.: 8 (391) 212-52-88 (служебн.); 8913 034-37-80 (моб.).

E-mail: olga-cet@yandex.ru
Парилова Ольга Владимировна

\section{Contacts:}

Olga V. Parilova

660022, Russian Federation, Krasnoyarsk, Partizana

Zheleznyaka str., 3G, Scientific Research Institute

of Medical Problems of the North.

Phone: +7 (391) 212-52-88 (office); +7 913 034-37-80 (mobile). E-mail: olga-cet@yandex.ru

\section{Библиографическое описание:}

Парилова О.В., Капустина Т.А., Маркина А.Н., Белова Е.В. Особенности иммунного ответа у больных с обострением хронического верхнечелюстного синусита, сопряженного с внутриклеточной бактериальной инфекцией // Инфекция и иммунитет. 2019. Т. 9, № 5-6. C. 687-694. doi: 10.15789/2220-7619-2019-5-6-687-694

(ㄷ Парилова О.В. и соавт., 2019

\section{Citation:}

Parilova O.V., Kapustina T.A., Markina A.N., Belova E.V. Characteristics of immune response in patients with acute chronic maxillary sinusitis associated with intra-cellular bacterial infections // Russian Journal of Infection and Immunity = Infektsiya i immunitet, 2019, vol. 9, no. 5-6, pp. 687-694. doi: 10.15789/2220-7619-2019-5-6-687-694

DOI: http://dx.doi.org/10.15789/2220-7619-2019-5-6-687-694 
инфекцией и пациентов с отрицательными тестами была выявлена общая направленность патологических изменений со стороны иммунной системы, соответствующая стандартному ответу организма на имеющейся воспалительный инфекционный процесс. Кроме этого были выявлены и особенности иммунореактивности у больных с верифицированной хламидийной инфекцией, заключающиеся в более выраженном дисбалансе в Т-клеточном звене иммунитета, а также в активации параметров гуморального звена иммунитета у больных с подтвержденным хламидийным и микоплазменным инфицированием.

Ключевые слова: Chlamydia trachomatis, Chlamydophila pneuтопіае, Mycoplasma рпеитопіае, хронический верхнечелюстной синусит, внутриклеточная бактериальная инфекция, иммунный ответ.

\title{
CHARACTERISTICS OF IMMUNE RESPONSE IN PATIENTS WITH ACUTE CHRONIC MAXILLARY SINUSITIS ASSOCIATED WITH INTRA-CELLULAR BACTERIAL INFECTIONS
}

\author{
Parilova O.V. a,b, Kapustina T.A. ${ }^{a}$, Markina A.N. ${ }^{\text {a }}$, Belova E.V. ${ }^{a}$ \\ ${ }^{a}$ Scientific Research Institute for Medical Problems of the North, Krasnoyarsk, Russian Federation \\ ${ }^{b}$ State Khakassia N.F. Katanov's University, Abakan, Russian Federation
}

\begin{abstract}
Currently, chronic inflammatory pathology of paranasal sinuses mostly affecting maxillary antrum is one of the pressing issues for health care. Over the last two decades, a great etiological importance in inducing inflammation in paranasal sinuses was referred to bacterial intracellular infections caused by Mycoplasma and Chlamydia. In particular, Chlamydia, whose life cycle is closely linked to residence inside host cells defines them as pathogenic obligate intracellular gram-negative bacteria, whereas Mycoplasma is a membrane-associated microorganism able to self-replication and long persistence on host cellular membranes. Increased incidence of chronic pathology in paranasal sinuses associated with intracellular infection is shaped by a range of circumstances, primarily increased prevalence of immunocompromised subjects, worsened social and ecological conditions, uncontrolled and unjustified administration of available of antimicrobials and anti-septic agents, hormone preparations altering community of extracellular microbe populations (microbiocenoses), inhabiting natural biotope in the upper respiratory tract mucosa. These factors contribute to the lowering colony resistance, entrance and propagation of Chlamydia and Mycoplasma as a mono- or mixed infection. Upon that, mixed variants of Chlamydia-Mycoplasma infection are characterized by development of more severe sinusitis accompanied with diverse complications in the lower respiratory tract, digestive tract, urinary and nerve system. There were examined 189 subjects for assessing epidemiologic characteristics and features of systemic and mucosal immune responses in patients with exacerbated chronic maxillary sinusitis associated with intracellular bacterial infection. Presence of intracellular bacterial infection was confirmed by laboratory tests: direct immune fluorescent analysis and PCR. It was found that high prevalence of Chlamydia trachomatis, Chlamydophila pneumoniae and Mycoplasma pneumoniae in patients with exacerbated chronic inflammatory pathology of paranasal sinuses. Comparing laboratory test data for patients with identified intracellular bacterial pathogens vs. those with negative results revealed a common trend in pathologic immune-related changes that fits to typical host anti-infection response manifested by inflammatory process. Besides, we described features of immune reactivity in patients with verified Chlamydia infection including more pronounced unbalance in $\mathrm{T}$ cell immunity as well as evelated parameters of humoral immunity in patients with verified Chlamydia and Mycoplasma infection.
\end{abstract}

Key words: Chlamydia trachomatis, Chlamydophila pneumoniae, Mycoplasma pneumoniae, chronic maxillary sinusitis, intracellular bacterial infection, immune response.

В последние годы с появлением новых современных методов диагностики инфекционных заболеваний появилась возможность всестороннего изучения характера микрофлоры, вызывающей воспалительные заболевания ЛОР-органов, включая атипичные патогены и в первую очередь хламидии и микоплазма. Для оториноларингологов большой интерес приставляют два вида хламидий - Chlamydia trachomatis и Chlamydophila pneumoniae, а также Mycoplasma pneumoniae. K настоящему времени получены достаточно убедительные данные, свидетельствующие о том, что сочетание внутриклеточной инфекции с традиционной микрофлорой зачастую создает максимально благоприятные условия для становления и хронизации заболеваний верхнего отдела респираторного тракта. Многообразие и неспецифичность клинических проявлений осложняет диагностику хламидиозов. Несмотря на совершенствование способов диагностики и лечения воспалительных хронических заболеваний носа, уровень их распространенности в настоящее время не уменьшается. Более того, наблюдается тенденция к увеличению числа рецидивирующих и хронических форм.

По данным эпидемиологических исследований, проведенных за последние 10 лет, заболеваемость риносинуситом увеличилась в 2 раза, а удельный вес госпитализированных по этому поводу больных вырастает ежегодно на 1,5-2\% $[4,9,10]$. Такие больные составляют более 1/3 
от общего числа госпитализированных в оториноларингологические отделения, а их доля колеблется от 29 до $60 \%$ [10, 13].

Установлено, что 5-15\% населения земного шара страдает той или иной формой хронического синусита, а затраты на их лечение составляют более чем 3,5 млрд долларов в год $[10,13,14]$. В среднем по России показатель обращаемости больных ПРС составляет 4,9 на 10000 населения, при этом отмечается около 70000 новых случаев ПРС в год [10]. Исходя из этих статистических данных, в России ПРС может встречаться примерно у 1 млн 400 тыс. человек. По данным шведских исследователей, ПРС страдает 2,7\%, в Южной Корее - 0,5\%, в Финляндии $-4,3 \%$, во Франции - 2,1\% от общей численности населения [13]. Во второй половине прошлого столетии ведущая роль в этиологии инфекционных заболеваний респираторного тракта принадлежала Streptococcus pneumoniae, доля которого составляла около $80 \%$, однако в конце $\mathrm{XX}$ в. удельный вес этой инфекции стал составлять лишь 25-36\% [7, 10, 14]. В 25-35\% заболеваний на искусственных питательных средах не удается выделить какого-либо возбудителя [7, 13]. Это обусловлено сменой спектра инфекционных агентов и связано с увеличением этиологической значимости внутриклеточной инфекции, в том числе и хламидий и микоплазмы [5, 8, 10].

Рост заболеваний, вызываемых атипичной инфекцией определяется многими обстоятельствами, прежде всего увеличением числа иммунокомпрометированных лиц, ухудшением социальных и экологических условий жизни, бесконтрольным применением антимикробных средств и гормонов, приводящих к появлению полирезистентных штаммов микроорганизмов, а также к значительному снижению клеточных и гуморальных факторов иммунитета [2, 3, 6, 11, 12].

Данные о частоте встречаемости хламидийной инфекции при воспалительной патологии ЛОР-органов существенно варьируют - от 7 до $74,4 \%[1,3,5,9,14]$. По данным различных исследований на долю микоплазменной инфекции среди заболеваний респираторного тракта приходится от 10 до 40\% случаев. Более высокий уровень заболеваемости отмечается у детей раннего возраста и лиц с ослабленным иммунитетом старше 65 лет [14, 15].

В среднем считается, что уровень инфицирования хламидиями взрослых здоровых лиц находится в пределах 8-10\%, микоплазмами 2-6\%. Вероятность развития инфекций увеличивается в 2-3 раза при неблагоприятных социально-экономических условиях, в 4-5 раз при циркуляции возбудителя в семье и рецидивирующем их течении. Смешанные варианты хламидийно-микоплазменной инфекции характеризуются развитием более тяжелых форм респираторных заболеваний (деструктивные и плевропневмонии) с функциональными расстройствами (синдром вегетативной дистонии, дискинезия желчевыводящих путей, вертебробазилярная недостаточность и др.).

Такая вариабельность показателей распространенности хламидийной инфекции при заболевании ЛОР-органов обусловлена различной организацией проводимых исследований, отсутствием стандартизированного комплекса методов лабораторной диагностики и взятия клинического материала. Известные способы выявления хламидийно-микоплазменного инфицирования слизистой оболочки верхнего отдела респираторного тракта основаны на использовании различных лабораторных тестов $[1,8$, $10,14]$. Диагностика хламидийной инфекции осуществляется непосредственным выявлением возбудителя, его структур, антигенов и нуклеиновых кислот в клинических образцах и косвенным подтверждением инфекции (определение специфических антител). Прямые тесты обнаружения хламидийной инфекции включают бактериоскопический (цитологический), иммунологический (прямой и непрямой иммунофлюоресцентный анализ, иммуноферментный анализ), культуральный, молекулярно-биологический (полимеразная цепная реакция, лигазная цепная реакция и транскрипционная амплификация) методы. К непрямым тестам относятся серологические методы (реакция связывания комплемента, реакция непрямой гемагглютинации, реакция непрямой иммунофлюоресценции, иммуноферментный анализ). Нами был разработан алгоритм лабораторной диагностики хламидий у лиц с подозрением на колонизацию ими слизистой оболочки верхнего отдела респираторного тракта, включающий два прямых метода и один непрямой метод индикации возбудителя.

Несвоевременное обнаружение хламидий в слизистой оболочке верхнего отдела полости носа, а также нераспознанная хламидийная инфекция приводят к тому, что больные получают традиционную противомикробную терапию, не элиминирующую хламидийную инфекцию. Это провоцирует удлинение периода обострения заболеваний, появление непрерывно-рецидивирующих форм, способствует развитию осложнений и утяжелению течения заболевания, содействует диссеминации хламидий в организме с последующим развитием экстрареспираторных очагов поражения.

Цель: изучение эпидемиологической характеристики и особенностей системного и мукозального иммунного ответов у населения Сибири с воспалительной патологией верхнего отдела респираторного тракта, сопряженной с внутриклеточной инфекцией. 


\section{Материалы и методы}

Проводилось определение двух видов хламидий (Chlamydia trachomatis и Chlamydophila pneumoniae), а также Mycoplasma pneumoniae. Для верификации антигенов этих микроорганизмов применялись прямой иммунофлуоресцентный анализ. Дополнительно для верификации хламидий применялась полимеразноцепная реакция (ВекторБест-ДНК-амли).

Клиническим материалом для прямого диагностирования хламидийной инфекции околоносовых пазух служили мазки-соскобы со слизистой оболочки общего и среднего носовых ходов, а также мазки отпечатки с биоптатов (полипов, грануляций и т.д.), взятых из гайморовых пазух во время операции.

Для описания бинауральных признаков вычислялись их относительные частоты и $95 \%$ доверительный интервал (95\% ДИ). Качественные порядковые признаки описывались в виде медианы (Мe), нижнего и верхнего квартилей $\left(\mathrm{Q}_{0,25}-\mathrm{Q}_{0,75}\right)$. Оценка значимости различий относительных показателей проводилась по критерию Стьюдента, точному критерию Фишера и критерию $\chi^{2}$. Сравнение порядковых данных осуществлялось с помощью критерия МаннаУитни. За максимально приемлемую вероятность ошибки 1 рода (р) принималась величина, равная 0,05 и менее.

Всего было обследовано на одновременное наличие внутриклеточной бактериальной инфекции 189 больных в возрасте от 15 до 65 лет, поступивших в ЛОР-отделение с обострением хронического гайморита, направленных в стационар, вследствие неэффективности лечения в поликлинических условиях. Диагностика ЛОР-заболеваний проводилась по общепринятой в оториноларингологии схеме. Шифровка диагнозов осушествлялась в соответствии с системой классификации болезней, травм и причин смерти (МКБ-10). Диагноз верхнечелюстного синусита подтверждался рентгенологическим обследованием околоносовых пазух. Группу контроля составили лица с обострением острого синусита, отрицательными тестами на наличие внутриклеточной бактериальной инфекции в количестве 47 человек, не имевших ЛОР-заболеваний.

\section{Результаты и обсуждение}

Внутриклеточное инфицирование выявлено у 88 из 189 больных, что составляет 46,6\% (ДИ $39,4-53,7)$. Положительные результаты на наличие хламидийных структур в слизистой оболочке носа имели место у 69 человек, что составило 36,5\% (95\% ДИ 29,6-43,4). У 47 человек была верифицирована C. pneumoniae $(24,9 \%, 95 \%$
ДИ 18,7-31,0), у $14-$ - . trachomatis $(7,4 \%, 95 \%$ ДИ 3,7-11,2). Одновременное наличие маркеров $C$. pneumoniae и C. trachomatis определялось у 8 пациентов (в 4,23\%, 95\% ДИ 1,4-7,1).

Положительные результаты на наличие микоплазменных структур в слизистой оболочке носа имели место у 44 больных [23,3\% (95\% ДИ 17,3-29,3)]. Положительные результаты на наличие моноинфицирования Mycoplasma pneumoniae получены у 19 человек $(10,1 \%, 95 \%$ ДИ 5,8-14,4). Микоплазменное микст-инфицирование с C. pneumoniae составило 8,5\% (95\% ДИ $0-3,4)$, a с C. trachomatis 6,4\% (95\% ДИ 2,9-9,8). Одновременное наличие всех внутриклеточных микроорганизмов имело место у 3 человек $(1,6 \%, 95 \%$ ДИ 0-3,4).

Сравнительный анализ лабораторных показателей проводился между 4 группами. Больные хроническими риносинуситами, ассоциированными с микоплазмой, составляли 1 группу $(\mathrm{n}=19)$, с хламидиями -2 группу $(\mathrm{n}=44)$, с микоплазмой и хламидиями -3 группу $(\mathrm{n}=25)$; условно здоровые лица, у которых не были диагностированы ЛОР-заболевания, сопутствующая инфекционная и тяжелая соматическая патология вошли в 4 группу $(\mathrm{n}=47)$.

Показатели развернутого анализа крови у инфицированных внутриклеточной инфекцией и здоровых лиц представлены в таблице 1. При сравнении средних показателей гемограммы у больных, инфицированных микоплазмами по сравнению с инфицированными хламидиями, статистически значимых различий получено не было.

Тогда как при сравнении с группой микстинфицирования у лиц с моно инфицированием M. pneumoniae наблюдалось снижение абсолютного содержания сегментоядерных нейтрофилов $(\mathrm{p}=0,03)$. При сравнении со здоровыми лицами у лиц с микоплазмозом имели место относительная эозинофилия $(\mathrm{p}=0,01)$, снижение относительного $(\mathrm{p}<0,001)$ и абсолютного $(\mathrm{p}=0,01)$ содержания лимфоцитов, увеличение относительного содержания нейтрофилов $(\mathrm{p}=$ $0,01)$ и абсолютного $(\mathrm{p}=0,002)$ и относительного содержания моноцитов $(\mathrm{p}=0,02)$. При сравнении средних показателей гемограммы больных, инфицированных всеми видами внутриклеточных инфекций и инфицированных хламидиями, статистически значимых различий получено не было. При сравнении с группой здоровых лиц в группе с микст инфицированием наблюдалось абсолютная и относительная эозинофилия ( $<<$ $0,001)$, увеличение относительного $(\mathrm{p}=0,003)$ и абсолютного содержания нейтрофилов $(\mathrm{p}<$ $0,001)$, снижение относительного содержания лимфоцитов $(\mathrm{p}=0,01)$ и моноцитов $(\mathrm{p}=0,02)$.

Так, у больных с наличием хламидийных агентов по сравнению с контролем имело место 
статистически значимое повышение относительной концентрации лейкоцитов $(\mathrm{p}=0,002)$ за счет сегментоядерных $(\mathrm{p}=0,04)$, моноцитов $(\mathrm{p}=0,02)$ и эозинофилов $(\mathrm{p}=0,001)$. Кроме этого, у больных обеих групп относительные показатели содержания эозинофилов также были выше $(\mathrm{p}<0,001)$.

Абсолютные и относительные показатели состояния клеточного звена иммунитета отражены в таблице 2. У больных, инфицированных микоплазмами, иммунологические нарушения Т-клеточного звена иммунитета характеризовались снижением относительного и абсолютного количества $\mathrm{CD}^{+} \mathrm{T}$-лимфоцитов $(\mathrm{p}=0,001)$, абсолютного количества $\mathrm{CD}^{+}$Т-лимфоцитов $(\mathrm{p}=0,007)$, а также увеличением относительного содержания $\mathrm{CD}^{+} 2^{+}$Т-лимфоцитов $(\mathrm{p}=0,01)$ и $\mathrm{CD}^{+}$Т-лимфоцитов $(\mathrm{p}=0,01)$ по сравнению с контрольными показателями, и снижением индекса CD4/CD8 ( $\mathrm{p}=0,01)$.

Кроме этого, у больных с идентифицированными микоплазмами имело место снижения абсолютного $(\mathrm{p}=0,03)$ и относительного $(\mathrm{p}=$ 0,06) содержания $\mathrm{CD} 16^{+}-$-клеток по сравнению с больными, инфицированными хламидиями, а по сравнению с микст-инфицированными снижение абсолютного количества $\mathrm{CD}^{+}-(\mathrm{p}=$ $0,04)$ и $\mathrm{CD}_{16}{ }^{+}$-лимфоцитов $(\mathrm{p}=0,04)$.

Таблица 1. Показатели развернутого анализа крови у больных с хроническими риносинуситами и у здоровых лиц (Me, $\left.\mathbf{Q}_{0,25}-\mathbf{Q}_{0,75}\right)$

Table 1. Indicators of the developed analysis of blood at patients with chronic rhinosinusitis and at healthy persons $\left(\mathrm{Me}, \mathrm{Q}_{0.25}-\mathrm{Q}_{0.75}\right)$

\begin{tabular}{|c|c|c|c|c|}
\hline $\begin{array}{c}\text { Показатели } \\
\text { Parameters }\end{array}$ & $\begin{array}{c}\text { Больные с наличием } \\
\text { микоплазменной } \\
\text { инфекции (группа 1) } \\
\text { Patients with the presence } \\
\text { of mycoplasmal infections } \\
\text { (group 1) } \\
\mathbf{n}=19 \\
\end{array}$ & \begin{tabular}{|c|} 
Больные с наличием \\
хламидийной \\
инфекции (группа 2) \\
Patients with the presence \\
of chlamydial infections \\
(group 2) \\
$\mathbf{n = 4 4}$ \\
\end{tabular} & \begin{tabular}{|c|} 
Больные с наличием \\
микст-инфекции \\
(группа 3) \\
Patients with \\
the presence of mixed \\
infection (group 3) \\
$\mathbf{n}=\mathbf{4 4}$ \\
\end{tabular} & $\begin{array}{c}\text { Контроль } \\
\text { (группа 4) } \\
\text { Control } \\
\text { (group 4) } \\
\mathbf{n}=\mathbf{1 0 1}\end{array}$ \\
\hline $\begin{array}{l}\text { Лейкоциты, 109/л } \\
\text { Leukocytes, 109\% }\end{array}$ & $5,7(4,6-6,3)$ & $6,5(4,9-8,0)$ & $\begin{array}{c}7,4(5,6-8,7) \\
p_{1-3}=0,02\end{array}$ & $\begin{array}{c}5,3(4,3-7,3) \\
\mathrm{p}_{2-4}=0,05 \\
\mathrm{p}_{3-4}<0,001\end{array}$ \\
\hline $\begin{array}{l}\text { Эозинофилы, \% } \\
\text { Eosinophils, \% }\end{array}$ & $2,0(1,0-4,0)$ & $3,0(2,0-5,0)$ & $3,5(2,0-6,0)$ & $\begin{array}{l}1,0(0,0-2,0) \\
\mathrm{p}_{1-4}=0,02 \\
\mathrm{p}_{2-4}<0,001 \\
\mathrm{p}_{3-4}<0,001\end{array}$ \\
\hline $\begin{array}{l}\text { Эозинофилы, } 10^{9} / л \\
\text { Eosinophils, } 10^{9} / \mathrm{L}\end{array}$ & $0,06(0,0-0,2)$ & $0,1(0,0-0,3)$ & $0,15(0,0-0,3)$ & $\begin{array}{l}0,5(0,0-0,1) \\
\mathrm{p}_{2-4}=0,005 \\
\mathrm{p}_{3-4}=0,004\end{array}$ \\
\hline $\begin{array}{l}\text { Сегментоядерные } \\
\text { лейкоциты, \% } \\
\text { Segmented leukocytes, \% }\end{array}$ & $60,0(51,0-72,0)$ & $61,0(48,0-67,0)$ & $62,0(55,0-68,0)$ & $\begin{aligned} & 55,0(46,0-60,0) \\
& p_{1-4}=0,03 \\
& p_{2-4}=0,06 \\
& p_{3-4}<0,01\end{aligned}$ \\
\hline $\begin{array}{l}\text { Сегментоядерные } \\
\text { лейкоциты, } 10^{9} / л \\
\text { Segmented } \\
\text { leukocytes, } 10^{9} / \mathrm{L}\end{array}$ & $3,1(2,6-4,4)$ & $3,4(2,3-4,7)$ & $\begin{array}{c}5,1(3,1-5,7) \\
p_{1-3}=0,02 \\
p_{2-3}=0,04\end{array}$ & $\begin{array}{c}3,0(2,3-3,8) \\
p_{3-4}<0,001\end{array}$ \\
\hline $\begin{array}{l}\text { Лимфоциты, \% } \\
\text { Lymphocytes, \% }\end{array}$ & $24,5(21,0-31,0)$ & $31,0(22,0-36,0)$ & $28,0(23,0-33,0)$ & $\begin{array}{c}40,0(35,0-46,0) \\
\mathrm{p}_{1-4}<0,001 \\
\mathrm{p}_{2-4}<0,001 \\
\mathrm{p}_{3-4}<0,001 \\
\end{array}$ \\
\hline $\begin{array}{l}\text { Лимфоциты, 109/л } \\
\text { Lymphocytes, } 10^{9} / \mathrm{L}\end{array}$ & $1,2(1,1-1,7)$ & $1,8(1,2-3,1)$ & $\begin{array}{c}1,6(1,4-2,7) \\
p_{1-3}=0,06\end{array}$ & $\begin{array}{c}2,1(1,4-2,8) \\
p_{1-4}<0,01\end{array}$ \\
\hline $\begin{array}{l}\text { Моноциты, \% } \\
\text { Monocytes, \% }\end{array}$ & $8,0(5,0-11,0)$ & $6,0(3,0-8,0)$ & $5,0(4,0-9,0)$ & $\begin{array}{c}4,0(2,0-6,0) \\
p_{1-4}<0,01 \\
p_{2-4}=0,01 \\
\end{array}$ \\
\hline $\begin{array}{l}\text { Моноциты, } 10^{9} / л \\
\text { Monocytes, } 10^{9} / \mathrm{L}\end{array}$ & $0,44(0,3-0,6)$ & $0,31(0,2-0,5)$ & $0,4(0,2-0,4)$ & $\begin{array}{l}0,2(0,9-0,35) \\
\mathrm{p}_{1-4}=0,01 \\
\mathrm{p}_{2-4}=0,01 \\
\mathrm{p}_{3-4}=0,01\end{array}$ \\
\hline $\begin{array}{l}\text { COЭ } \\
\text { Erythrocyte } \\
\text { sedimentation rate }\end{array}$ & $6,0(3,0-10,0)$ & $6,0(3,0-15,0)$ & $4,0(2,0-26,0)$ & - \\
\hline
\end{tabular}

Примечание. p - статистическая значимость различий по критерию Манна-Уитни. Note. $p$ - statistically significant differences versus by Mann-Whitney criterion. 
Таблица 2. Показатели клеточного иммунитета у больных с хроническими синуситами и у здоровых лиц (ME, $\left.\mathbf{Q}_{0,25}-\mathbf{Q}_{0,75}\right)$

Table 2. Indices of cellular immunity in patients with chronic sinusitis and in healthy individuals $\left(\mathrm{Me}, \mathrm{Q}_{0.25}-\mathrm{Q}_{0.75}\right)$

\begin{tabular}{|c|c|c|c|c|}
\hline $\begin{array}{c}\text { Показатели } \\
\text { Parameters }\end{array}$ & $\begin{array}{c}\text { Больные с наличием } \\
\text { микоплазменной } \\
\text { инфекции (группа 1) } \\
\text { Patients with the presence } \\
\text { of mycoplasmal infections } \\
\text { (group 1) } \\
\text { n = 19 }\end{array}$ & $\begin{array}{c}\text { Больные с наличием } \\
\text { хламидийной } \\
\text { инфекции (группа 2) } \\
\text { Patients with the presence } \\
\text { of chlamydial infections } \\
\text { (group 2) } \\
\mathbf{n}=\mathbf{4 4}\end{array}$ & $\begin{array}{c}\text { Больные с наличием } \\
\text { микст-инфекции } \\
\text { (группа 3) } \\
\text { Patients with } \\
\text { the presence of mixed } \\
\text { infection (group 3) } \\
\mathbf{n}=\mathbf{2 5}\end{array}$ & $\begin{array}{c}\text { Контроль } \\
\text { (группа 4) } \\
\text { Control } \\
\text { (group 4) } \\
\text { n= 101 }\end{array}$ \\
\hline $\mathrm{CD3}^{+}, \%$ & $66,0(58,0-72,0)$ & $61,0(52,0-66,0)$ & $\begin{array}{l}66(58-72) \\
p_{2-3}=0,06\end{array}$ & $\begin{array}{l}66(63-70) \\
p_{2-4}<0,01\end{array}$ \\
\hline $\mathrm{CD}^{+}, 10^{9} / \mathrm{L}$ & $1,34(0,9-1,7)$ & $1,1(0,7-1,6)$ & $\begin{array}{c}1,3(0,9-1,7) \\
p_{1-3}=0,05\end{array}$ & $\begin{array}{c}1,5(1,0-1,9) \\
p_{1-4}<0,01 \\
p_{2-4}=0,02\end{array}$ \\
\hline $\mathrm{CD4}^{+}, \%$ & $39,0(34,0-45,0)$ & $36,0(24-44)$ & $39(34-45)$ & $\begin{array}{l}42(35-46) \\
\mathrm{p}_{1-4}<0,01 \\
\mathrm{p}_{2-4}=0,01\end{array}$ \\
\hline $\mathrm{CD}^{+}, 10^{9} / \mathrm{L}$ & $0,8(0,6-1,14)$ & $0,6(0,4-1,0)$ & $\begin{array}{c}0,8(0,6-1,1) \\
p_{1-3}=0,03\end{array}$ & $\begin{array}{c}1,0(0,6-1,2) \\
p_{1-4}<0,001 \\
p_{2-4}<0,01\end{array}$ \\
\hline $\mathrm{CD}^{+}, \%$ & $32,0(27,0-36,0)$ & $\begin{array}{c}26,5(23,0-30,0) \\
p_{1-2}=0,04\end{array}$ & $\begin{array}{l}28(24-32) \\
p_{1-3}=0,08\end{array}$ & $\begin{array}{l}24(22-30) \\
p_{1-4}<0,01\end{array}$ \\
\hline $\mathrm{CD8}^{+}, 10^{9} / \mathrm{L}$ & $0,42(0,27-0,6)$ & $0,5(0,3-0,8)$ & $0,5(0,4-0,8)$ & $0,6(0,4-0,7)$ \\
\hline CD16 ${ }^{+}, \%$ & $16,0(12,0-22,0)$ & $\begin{array}{c}21,5(15,0-28,0) \\
p_{1-2}=0,06\end{array}$ & $19(11-24)$ & 21 (17-23) \\
\hline $\mathrm{CD}_{16}{ }^{+}, 10^{9} / \mathrm{L}$ & $0,17(0,13-0,3)$ & $\begin{array}{c}0,42(0,2-0,6) \\
p_{1-2}=0,03\end{array}$ & $0,4(0,2-0,6)$ & $\begin{array}{c}0,4(0,3-0,6) \\
p_{1-4}<0,01\end{array}$ \\
\hline $\mathrm{CD}^{2}{ }^{+}, \%$ & $17,0(14,0-22,0)$ & $16(10-21)$ & $\begin{array}{l}16(12-17) \\
p_{1-3}=0,07\end{array}$ & $\begin{array}{c}14(10-15) \\
p_{1-4}=0,005\end{array}$ \\
\hline $\mathrm{CD}^{2}{ }^{+}, 10^{9} / \mathrm{L}$ & $0,24(0,2-0,3)$ & $0,23(0,14-0,46)$ & $0,3(0,2-0,4)$ & $0,29(0,17-0,4)$ \\
\hline CD4/CD8 & $1,1(1,0-1,3)$ & $1,4(0,9-1,8)$ & $\begin{array}{c}1,3(1,0-1,9) \\
p_{1-3}=0,05\end{array}$ & $\begin{array}{c}1,6(1,3-2,0) \\
p_{1-4}<0,001 \\
p_{2-4}=0,02\end{array}$ \\
\hline $\begin{array}{l}\text { ЦИК } \\
\text { Circulating immune } \\
\text { complex }\end{array}$ & $13,5(4,0-28,0)$ & $16(10-32)$ & $\begin{array}{c}26(20-110) \\
p_{1-3}=0,07\end{array}$ & $\begin{array}{c}24(7,5-36,0) \\
p_{3-4}=0,06\end{array}$ \\
\hline
\end{tabular}

Примечание. p - статистическая значимость различий по критерию Манна-Уитни.

Note. $p$ - statistically significant differences versus by Mann-Whitney criterion.

\section{Таблица 3. Показатели гуморального иммунитета у лиц с хроническими риносинуситами} и у здоровых лиц (ME, $\left.\mathbf{Q}_{0,25}-\mathbf{Q}_{0,75}\right)$

Table 3. Indices of humoral immunity in patients with chronic sinusitis and in healthy individuals $\left(\mathrm{Me}, \mathrm{Q}_{0.25}-\mathrm{Q}_{0.75}\right)$

\begin{tabular}{|c|c|c|c|c|}
\hline $\begin{array}{c}\text { Показатели } \\
\text { Parameters }\end{array}$ & $\begin{array}{c}\text { Больные с наличием } \\
\text { микоплазменной } \\
\text { инфекции (группа 1) } \\
\text { Patients with the presence } \\
\text { of mycoplasmal infections } \\
\text { (group 1) } \\
\mathbf{n}=19\end{array}$ & $\begin{array}{c}\text { Больные с наличием } \\
\text { хламидийной } \\
\text { инфекции (группа 2) } \\
\text { Patients with the presence } \\
\text { of chlamydial infections } \\
\text { (group 2) } \\
\mathbf{n}=\mathbf{4 4}\end{array}$ & $\begin{array}{c}\text { Больные с наличием } \\
\text { микст-инфекции } \\
\text { (группа 3) } \\
\text { Patients with } \\
\text { the presence of mixed } \\
\text { infection (group 3) } \\
\mathbf{n}=\mathbf{2 5}\end{array}$ & $\begin{array}{c}\text { Контроль } \\
\text { (группа 4) } \\
\text { Control } \\
\text { (group 4) } \\
\text { n= 101 }\end{array}$ \\
\hline $\lg A, g / \operatorname{l}$ & $3,2(2,7-3,6)$ & $2,8(1,8-3,9)$ & $2,1(1,8-3,2)$ & $\begin{array}{c}1,44(1,32-2,65) \\
p_{1-4}=0,01 \\
p_{2-4}<0,01 \\
p_{3-4}=0,02\end{array}$ \\
\hline $\lg M, g / I$ & $1,6(1,1-1,6)$ & $1,47(0,85-1,9)$ & $1,4(1,1-2,0)$ & $1,25(0,54-1,8)$ \\
\hline $\lg G, g / l$ & $13(12-14)$ & $12,2(8,6-15,2)$ & $11,2(8,8-14,4)$ & $\begin{array}{c}9,0(7,5-10,3) \\
p_{1-4}<0,001 \\
p_{2-4}<0,01\end{array}$ \\
\hline IgE, ME/ml & $18(18-18)$ & $\begin{array}{l}35(10-234) \\
p_{1-2}<0,001\end{array}$ & $\begin{array}{l}38(18-42) \\
p_{1-3}<0,001\end{array}$ & - \\
\hline
\end{tabular}

Примечание. $\mathrm{p}$ - статистическая значимость различий по критерию Манна-Уитни. Note. $p$ - statistically significant differences versus by Mann-Whitney criterion. 
При сравнении группы больных с микстинфицированием с группами с хламидийным инфицированием и здоровыми статистически значимых различий выявлено не было.

Помимо этого, были обнаружены некоторые различия в системном Т-клеточном иммунном ответе между больными, инфицированными хламидиями, и контрольной группой. Так, у больных с идентифицированной хламидийной инфекцией имело место статистически значимое снижение относительного и абсолютного содержания Т-лимфоцитов с фенотипом $\mathrm{CD}^{+}($соответственно $\mathrm{p}=0,01, \mathrm{p}=0,05)$ и $\mathrm{CD}^{+}$ (соответственно $\mathrm{p}=0,006, \mathrm{p}=0,03$ ).

Содержание циркулирующих иммунных комплексов было резко увеличено у больных с микст-инфицированием и равнялось 69,6 г/л [статистически значимые различия по сравнению с группой больных с хламидиями $(\mathrm{p}=0,05)$ и здоровыми $(\mathrm{p}=0,01)]$.

Средние показатели гуморального иммунитета у больных с верифицированной внутриклеточной инфекцией, а также в группе контроля представлены в таблице 3. Статистически значимые различия показателей гуморального иммунитета были получены при сопоставлении уровней $\operatorname{IgA}$ и IgG больных всех групп со здоровыми лицами (табл. 3). При этом концентрация IgG была выше у пациентов с внутриклеточной инфекцией. Кроме того, уровень IgA у пациентов с микст-инфицированием, по сравнению с больными 1 и 2 групп, было ниже $(\mathrm{p}=0,01$ и $\mathrm{p}=0,05)$.

\section{Выводы}

Проведенные нами исследования показали, что у больных с обострением хронического гайморита и неаллергического ринита (различные формы вазомоторного ринита), госпитализи- рованных в связи с неэффективностью амбулаторного лечения, внутриклеточная инфекция выявляется у половины пациентов, из них ведущее место принадлежит хламидийному инфицированию.

По видовому распределению первое место занимает $C$. pneumoniae - она выявлялась в 2 раза чаще, чем C. trachomatis, и была идентифицирована у 55 человек $(29,1 \%, 95 \%$ ДИ 22,6$35,6)$, против $22(11,6 \%, 95 \%$ ДИ 7,1-16,2) (р < 0,001). Второе место занимает M. pneumoniae 44 больных (23,3\%, 95\% ДИ 17,3-29,3).

У больных, несмотря на имеющиеся различия в содержании тех или иных параметров крови, наблюдаются однонаправленные патологические изменения показателей общего развернутого анализа крови по сравнению со здоровыми лицами.

У лиц с хроническими риносинуситами, независимо от вида внутриклеточного микроорганизма, отмечен ряд сходных изменений со стороны параметров клеточного звена иммунитета, которые в своей совокупности отражают дисбаланс его эффекторных компонентов на фоне иммунологической недостаточности.

Изменения в лейкограмме и в иммунограмме у лиц с внутриклеточным инфицированием по сравнению со здоровыми лицами соответствуют стандартному ответу организма на имеющейся воспалительный инфекционный процесс, что проявляется угнетением Т-клеточного и активацией В-клеточного звеньев иммунитета. Проведенные исследования доказали существование особенностей в иммунореактивности больных, заключающиеся в том, что при присоединении хламидийной инфекции имеет место более выраженный дисбаланс в Т-клеточном звене иммунитета. При внутриклеточном инфицировании наблюдается активация гуморального иммунного ответа.

\section{Список литературы/References}

1. Белова Е.В., Капустина Т.А., Маркина А.Н., Парилова О.В Алгоритм лабораторной диагностики хламидийной инфекции у больных хроническим синуситом // Вестник оториноларингологии. 2015. T. 80, № 4. C. 61-64. [Belova E.V., Kapustina T.A., Markina A.N., Parilova O.V. The algorithm for laboratory diagnostics of chlamydial infection in the patients presenting with chronic sinusitis. Vestnik otorinolaringologii $=$ Bulletin of Otorhinolaryngology, 2015, vol. 80, no. 4, pp. 61-64. doi: 10.17116/otorino201580461-64. (In Russ.)]

2. Борцов П.А., Федина Е.Д., Токарская Е.А., Мартынова В.Р., Зигангирова Н.А., Гинцбург А.Л. Регуляция хламидиями апоптоза клеток хозяина // Журнал микробиологии, эпидемиологии и иммунобиологии. 2006. № 4. С. 53-58. [Bortsov P.A., Fedina E.D., Tokarskaya E.A., Martynova V.R., Zigangirova N.A., Gintsburg A.L. Apoptosis of host cells regulation by chlamydia. Zhurnal mikrobiologii, epidemiologii i immunobiologii = Journal of Microbiology, Epidemiology and Immunobiology, 2006, vol. 80, no. 4, pp. 53-58. (In Russ.)]

3. Капустина Т.А., Савченко А.А., Парилова О.В., Коленчукова О.А., Кин Т.И., Лопатникова Е.В. Иммунопатологические нарушения у больных с хроническим риносинуситом, сопряженным с хламидийной инфекцией // Якутский медицинский журнал. 2010. № 3 (31). C. 31-35. [Kapustina T.A., Savchenko A.A., Parilova O.V., Kolenchukova O.A., Kin T.I., Lopatnikova E.V. Immunopathological disorders in patients with chronic rhinosinusitis, interfacing with Chlamydia infection. Yakutskiy meditsinskiy zhurnal = Yakut Medical Journal, 2010, no. 3(31), pp. 31-35. (In Russ.)]

4. Козлов В.С., Савлевич Е.Л. Полипозный риносинусит. Современные подходы к изучению патогенеза, диагностике и лечению // Вестник оториноларингологии. 2015. № 4. С. 95-99. [Kozlov V.S., Savlevich E.L. Chronic rhinosinusitis with nasal polyps. The recent trend in the studies of the pathogenesis, diagnosis and treatment of this disease. Vestnik otorinolaringologii = Bulletin of Otorhinolaryngology, 2015, no. 4, pp. 95-99. doi: 10.17116/otorino201580495-99 (In Russ.)] 
5. Лиханова М.А., Бондарев О.И., Мингалев Н.В., Лебедева Р.Н. Полипозным риносинусит - вопросы этиопатогенеза // Омский научный вестник. 2014. № 2 (134). С. 56-59. [Likhanova M.A., Bondarev O.I., Mingalev N.V., Lebedeva R.N. Polypoid rhinosinusitis - questions etiopathogenesis. Omskiy nauchnyy vestnik = Omsk Scientific Bulletin, 2014, no. 2 (134), pp. 56-59. (In Russ.)]

6. Лобзин Ю.В., Сидорчук А.Л., Позняк С.Н. Клинико-лабораторная диагностика хламидия-индуцированных артропатий // Эпидемиология и инфекционные болезни. 2010. № 6. C. 48-51. [Lobzin Yu.V., Sidorchuk S.N., Poznyak A.L. Clinical laboratory diagnosis of Chlamydia-induced arthropathies. Epidemiologiya $i$ infektsionnye bolezni $=$ Epidemiology and Infectious Diseases, 2010, no. 6, pp. 48-51. (In Russ.)]

7. Лопатин А.С., Иванченко О.А., Гаврилов П.П., Карпищенко С.А., Козлов Р.С., Кречикова О.И., Кухаренко О.А., Отвагин И.В., Сказатова О.И., Сопко О.Н., Пискунов Г.З. Микробный пейзаж верхнечелюстных пазух и среднего носового хода при хроническом риносинусите // Российская ринология. 2013. Т. 21, № 4. С. 4-8. [Lopatin A.S., Ivanchenko O.A., Gavrilov P.P., Karpishchenko S.A., Kozlov R.S., Krechikova O.I., Kukharenko O.A., Otvagin I.V., Skazatova O.I., Sopko O.N., Piskunov G.Z. Characteristics of microflora in maxillary sinuses and middle nasal meatuses during chronic rhinosinusitis. Rossiyskaya rinologiya $=$ Russian Rhinology, 2013, vol. 21, no. 4, pp. 4-8. (In Russ.)]

8. Маянский А.Н. Микробиология и клинические проявления хламидиозов // Вопросы диагностики в педиатрии. 2012. T. 4, № 5. C. 10-19. [Mayanskiy A.N. Microbiology and clinical features of chlamydiosis. Voprosy diagnostiki v pediatrii $=$ The Diagnostics in Pediatrics, 2012, vol. 4, no. 5, pp. 10-19. (In Russ.)]

9. Михайлов Ю.Х. Некоторые теоретические и методологические проблемы современной ринологии // Военно-медицинский журнал 2006. № 6. С. 52-56. [Mikhaylov Yu.H. Some theoretical and methodological problems of modern rhinology. Voenno-meditsinskiy zhurnal $=$ Military Medical Journal, 2006, no. 6, pp. 52-56. (In Russ.)]

10. Пальчун В.Т., Гуров А.В., Руденко В.В. Хламидийная и микоплазменная инфекция в оториноларингологии (систематический обзор) // Вестник оториноларингологии. 2012. № 6. C. 91-97. [Pal'chun V.T., Gurov A.V., Rudenko V.V. Chlamygial and mycoplasmal infections in otorhinolaryngology (a systematic review). Vestnik otorinolaringologii $=$ Bulletin of Otorhinolaryngology, 2012, no. 6, pp. 91-97. (In Russ.)]

11. Федорова В.А., Султанахмедов Э.С., Салтыков Ю.В., Утц С.Р., Мотин В.Л. Совершенствование лабораторной диагностики урогенитальной хламидийной инфекции у пациентов с нарушением репродуктивной функции, инфицированных Chlamydia trachomatis // Вестник дерматологии и венерологии. 2017. № 2. C. 34-44. [Fedorova V.A., Sultanakhmedov E.S., Saltykov Yu.V., Utts S.R., Motin V.L. Improvement of laboratory diagnostics of urogenital chlamydial infection in patients with impaired reproductive function infected with Chlamydia trachomatis. Vestnik dermatologii $i$ venerologii $=$ Vestnik Dermatologii i Venerologii, 2017, no. 2, pp. 34-44. doi: 10.25208/0042-4609-2017-0-2-34-44 (In Russ.)]

12. Хрянин А.А. Урогенитальная хламидийная инфекция у женщин: тактика ведения пациенток в соответствии с современными зарубежными и российскими рекомендациями // Вестник дерматологии и венерологии. 2015 . № 2. C. 101-110. [Khryanin A.A. Urogenital chlamydial infection in women: tactics of conducting patients in accordance with modern foreign and Russian recommendations. Vestnik dermatologii i venerologii = Vestnik Dermatologii $i$ Venerologii, 2015, no. 2, pp. 101110. doi: 10.25208/0042-4609-2015-0-2-101-110. (In Russ.)]

13. Fokkens W.J., Lund V.J., Mullol J., Bachert C., Alobid I., Baroody F., Cohen N., Cervin A., Douglas R., Gevaert P., Georgalas C., Goossens H., Harvey R., Hellings P., Hopkins C., Jones N., Joos G., Kalogjera L., Kern B., Kowalski M., Price D., Riechelmann H., Schlosser R., Senior B., Thomas M., Toskala E., Voegels R., de Wang Y., Wormald P.J. EPOS 2012: European position paper on rhinosinusitis and nasal polyps 2012. A summary for otorhinolaryngologists. Rhinol. Suppl., 2012, vol. 50, no. 23 , pp. 1-12. doi: 10.4193/Rhino50E2

14. Javadi Nia S., Zarabi V., Noorbakhsh S., Farhadi M., Ghavidel Darestani S. Chlamydophila pneumoniae infection assessment in children with adenoid hypertrophy concomitant with rhino sinusitis. Jundishapur J. Microbiol., 2014, vol. 7, no. 8: e11134. doi: $10.5812 /$ jjm.11134

15. Principi N., Esposito S. Mycoplasma pneumoniae and Chlamydia pneumoniae cause lower respiratory tract disease in paediatric patients. Curr. Opin. Infect. Dis., 2002, vol. 15, no. 3, pp. 295-300.

\section{Авторы:}

Парилова О.В., к.М.Н., ведущий научный сотрудник лаборатории клинической патофизиологии ФГБНУ НИИ медицинских проблем Севера, г. Красноярск, Россия; доцент кафедры общепрофессиональных дисциплин ФГБОУ ВО Хакасский государственный университет им. Н.Ф. Катанова, г. Абакан, Россия;

Капустина Т.А., д.м.н., главный научный сотрудник лаборатории клинической патофизиологи ФГБНУ НИИ медицинских проблем Севера, г. Красноярск, Россия;

Маркина А.Н., к.м.н., старший научный сотрудник лаборатории клинической патофизиологии ФГБНУ НИИ медицинских проблем Севера, г. Красноярск, Россия;

Белова Е.В., К.М.н., старший научный сотрудник лаборатории клинической патофизиологии ФГБНУ НИИ медицинских проблем Севера, г. Красноярск, Россия.

\section{Authors:}

Parilova O.V., PhD (Medicine), Leading Researcher, Laboratory of Clinical Pathophysiology, Scientific Research Institute of Medical Problems of the North, Krasnoyarsk, Russian Federation; Associate Professor, Department of General Professional Disciplines, Abakan, Russian Federation;

Kapustina T.A., PhD, MD (Medicine), Head Researcher, Laboratory of Clinical Pathophysiology, Scientific Research Institute of Medical Problems of the North, Krasnoyarsk, Russian Federation; Markina A.N., PhD (Medicine), Senior Researcher, Laboratory of Clinical Pathophysiology, Scientific Research Institute of Medical Problems of the North, Krasnoyarsk, Russian Federation;

Belova E.V., PhD (Medicine), Senior Researcher, Laboratory of Clinical Pathophysiology, Scientific Research Institute of Medical Problems of the North, Krasnoyarsk, Russian Federation.
Поступила в редакцию 23.03.2018

Отправлена на доработку 10.03.2019

Принята к печати 22.03.2019
Received 23.03.2018

Revision received 10.03.2019

Accepted 22.03.2019 